\title{
Comparison of complications between transcatheter and surgical ventricle septal defect closure: a single-center cohort study
}

Deny Salverra Yosy, ${ }^{1}$ Mulyadi Muhammad Djer, ${ }^{2}$ Sukman Tulus Putra ${ }^{2}$

pISSN: 0853-1773 • elSSN: 2252-8083 https://doi.org/10.13181/mji.oa.203837 Med J Indones. 2020;29:268-74

Received: June 16, 2019

Accepted: July 06, 2020

Published online: August 07, 2020

Authors' affiliations:

${ }^{1}$ Department of Child Health, Medical

School, Universitas Sriwijaya/

Mohammad Hoesin Hospital,

Palembang, Indonesia, '2Department of Child Health, Faculty of Medicine,

Universitas Indonesia, Cipto

Mangunkusumo Hospital, Jakarta,

Indonesia

\section{Corresponding author:}

Deny Salverra Yosy

Department of Child Health, Medical

School, Universitas Sriwijaya/

Mohammad Hosein Hospital, Jalan Jend.

Sudirman km 3.5, Palembang 30126,

Indonesia

Tel/Fax: +62-711-376445/

+62-711-351318

E-mail: ochie_dr@yahoo.co.id

\begin{abstract}
BACKGROUND Some ventricular septal defects (VSDs) require an interventional procedure for closure. Transcatheter and surgical closures of VSD have similar effectiveness, but transcatheter VSD closure is considered associated with less complication than surgical closure. This study aimed to compare mid-term or long-term complications of transcatheter and surgical VSD closures.
\end{abstract}

METHODS This was a retrospective cohort study compared the complication rates of transcatheter and surgical VSD closures performed in Cipto Mangunkusumo Hospital from January 1, 2010, to April 30, 2017, with 34 subjects in each group. The inclusion criteria were as follows: single lesion outlet perimembranous or doubly committed subarterial VSD, age 2-18 years, body weight $>8 \mathrm{~kg}$, and no arrhythmia. Electrocardiography and echocardiography were done to collect primary data. Other data were collected from medical records. Mid-term complications occurred 1-24 months after interventional closure. Long-term complications occurred 24 months after interventional closure. Complications were arrhythmia, valve regurgitation, and residual shunt. Data were analyzed by chi-square test.

RESULTS The rate of worsening valve regurgitation was higher in the transcatheter group than in the surgical group (16 versus $11, p=0.322$ ). The number of patients with residual shunts were similar between the transcatheter group and surgical group ( 5 versus $5 ; p=1.000$ ). Both complications were found in mid- and long-term. Arrhythmia as a long-term complication occurred in five and seven patients in the transcatheter and surgical groups, respectively $(p=0.752)$.

CONCLUSIONS Transcatheter and surgical VSD closures have similar mid- or long-term complications.

KEYWORDS complication, surgery, transcatheter, ventricular septal defect
Ventricular septal defect (VSD), the most common congenital heart disease (CHD), is characterized by a defect or a hole in the septum separating the left ventricle and the right ventricle. ${ }^{1}$ VSD is estimated to occur in $20-30 \%$ of all CHD cases and perimembranous VSD (PM VSD) accounts for approximately $70 \%$ of all VSDs. ${ }^{1}$

VSD is divided according to the location of the defect: perimembranous outlet VSD (PMO VSD), doubly committed subarterial VSD (DCSA VSD), perimembranous inlet VSD, and muscular VSD. ${ }^{1}$ The disease course of VSD widely varied, ranging from spontaneous closure to death in early infancy. Spontaneous closure usually occurs at age 2 years and uncommon after age 4 years, though it has ever been reported in adults. ${ }^{2}$ Spontaneous closure most commonly occurs in muscular defects ( $80 \%)$, followed by perimembranous defects $(35-40 \%)$ and small 
defects. PMO VSDs have a low rate of spontaneous closure at age 2 years until 4 years (7.3\%), while perimembranous inlet VSDs almost never close spontaneously. ${ }^{3}$

Before the interventional cardiology era, VSD closure was done by the surgery alone, which is still the current gold standard. The complications often occur during and after VSD closure due to the use of a cardiopulmonary bypass (CPB). These complications can lead to developmental problems in pediatric patients. ${ }^{4}$ Transcatheter closure of the VSD is considered more efficient, especially for hospitals with limited human resources and facilities, because it does not require special monitoring in the intensive care unit after the procedure; thus, it may reduce maintenance costs. It is also considered less lifethreatening because CPB is not needed. However, not all VSDs can be closed via the transcatheter approach, including large-sized VSD which is usually accompanied by heart failure and VSD in complex CHD. Moreover, controversy arises for the device used, that is, whether it can cause compression on the conduction pathway and heart rhythm disorders. ${ }^{5}$

The most commonly observed complications after transcatheter VSD closure are heart rhythm disorders, aortic and tricuspid valve regurgitation, residual shunt, thrombosis, hemolysis, and embolization. ${ }^{5}$ One of the serious complications of transcatheter VSD closure is total atrioventricular (AV) block which occurred in $2 \%$ of cases during nearly 2 years of followup. Hence, long-term monitoring is necessary. Aortic and tricuspid regurgitations can be mid-term or long-term complications of transcatheter or surgical VSD closure, ${ }^{6}$ and the residual shunt is another complication.?

Complications of transcatheter and surgical VSD closures are often missed during monitoring, resulting in the late intervention. Therefore, this study aimed to monitor mid- and long-term complications through echocardiography and electrocardiography (ECG) and to compare the complications in both procedures, including heart rhythm disorders, valve regurgitation, and residual shunts in our center.

\section{METHODS}

\section{Study design}

This retrospective cohort study was conducted at Cipto Mangunkusumo Hospital from March to May
2017. Data were taken from electronic health records of all subjects with PMO VSDs and DCSA VSDs attending the Integrated Heart Service of subjects between January 1, 2010, and April 30, 2017. Parents of children who met the inclusion criteria were then contacted by telephone for participation, examination, and appointment for ECG and echocardiography between March 1 and May 30, 2017. ECG and echocardiography were performed by a pediatric trainee cardiologist and confirmed by a consultant pediatric cardiologist.

Sampling was done consecutively. The inclusion criteria were as follows: (1) subjects with single lesion PMO or DCSA VSD who had transcatheter or surgical VSD closure and (2) age 2-18 years and/or body weight $\geq 8 \mathrm{~kg}$ at the time of VSD closure. The exclusion criteria were as follows: (1) VSD subjects with complex CHD, (2) inlet and muscular VSD subjects, (3) incomplete medical record data, (4) unwilling to participate in the mid-term or long-term monitoring, and (5) history of arrhythmias prior to VSD closure.

Every subject was classified to have mid-term or long-term complications according to the results of the last examination after interventions. Mid-term complications were measured 1-24 months after transcatheter and surgical VSD closures, while longterm complications were measured 24 months after VSD closure. ${ }^{8}$ Arrhythmia was defined as an abnormal heart rhythm outside the sinus rhythm based on the ECG recorded at the time of monitoring. Residual shunt was the presence of flow from the left ventricle to the right ventricle as detected by transthoracic color Doppler echocardiography with the following classification: (a) trivial (<1 mm), (2) small (1-2 mm), (3) moderate $(>2-4 \mathrm{~mm})$, and (d) large $(>4 \mathrm{~mm}) \cdot{ }^{9}$ Valve regurgitation was assessed by jet areas on color Doppler transthoracic echocardiography with the following classification: mild, moderate, and severe.

VSD size before VSD closure was based on transthoracic echocardiography data, including (1) small VSD, defect size less than $1 / 2$ diameter of the aortic annulus; (2) moderate VSD, defect size $1 / 2$ diameter of the aortic annulus; and (3) large VSD, defect size equal to or greater than the aortic annulus diameter. The aortic annulus diameter of infants and young children and of older children and adults are 10 and $20 \mathrm{~mm}$, respectively. ${ }^{9}$ The right atrial approach is a technique for VSD closure in which the tricuspid valve leaflets are retracted to expose the location of the VSD. The transpulmonary arterial approach is a 
technique for VSD closure in which the right atrial approach is accomplished through a vertical incision in the pulmonary trunk. ${ }^{9}$

\section{Statistical analyses}

The number of samples was calculated based on a minimum sample size of each procedure by using a formula for differences in the proportion of transcatheter and surgical complications. We assumed an alpha value of $5 \%$ and beta value of $20 \%$, with $p 1$ (proportion of complication of surgical VSD closure according to literature) ${ }^{10}$ of 0.323 and $\mathrm{p} 2$ (proportion of complication of transcatheter VSD closure according to literature $)^{10}$ of 0.07 . Differences in the proportion of arrhythmia events, changes in the severity of valve regurgitation, and residual shunts between the transcatheter and surgical groups were analyzed by chisquare with $95 \%$ confidence interval and significance value at $p<0.05$

\section{Ethical approval}

This study received ethical approval from the Ethics Committee of the Faculty of Medicine, Universitas Indonesia (No: 171/UN2.F1/ETIK/2017).

\section{RESULTS}

In total, 115 and 72 subjects with PMO VSDs and DCSA VSDs underwent transcatheter and surgical closures, respectively, but only 34 subjects in each treatment were eligible to participate in the monitoring. The flowchart diagram of the subject's recruitment is shown in Figure 1. The subjects' characteristics are shown in Table 1.

PM VSD was more prevalent in the transcatheter group than in the surgical group, whereas DCSA VSD was more common in the surgical group. In this study, 32 subjects had small VSD, 20 subjects had moderate VSD, and 16 subjects had large VSD. Small VSD accounted

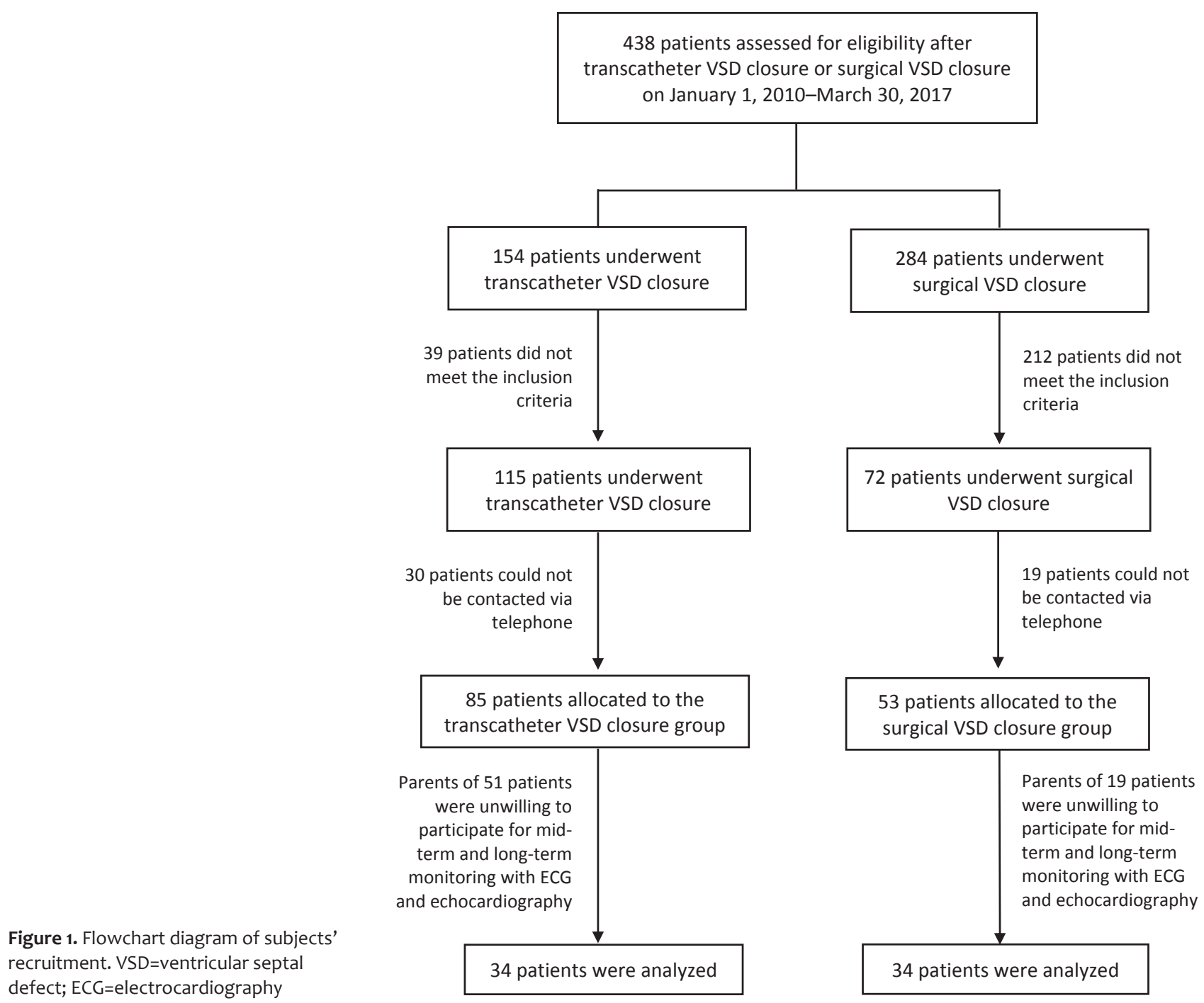

mji.ui.ac.id 
Table 1. Subjects' characteristics

\begin{tabular}{|c|c|c|}
\hline \multirow{2}{*}{ Characteristic } & \multicolumn{2}{|c|}{ Procedure } \\
\hline & Transcatheter, $\mathrm{n}(\mathrm{N}=34)$ & Surgery, $\mathrm{n}(\mathrm{N}=34)$ \\
\hline \multicolumn{3}{|l|}{ Sex } \\
\hline Boy & 17 & 22 \\
\hline Girl & 17 & 12 \\
\hline Age at the procedure (years), mean (SD) & $6.1(4.4)$ & $5.6(3.4)$ \\
\hline Body weight at the procedure $(\mathrm{kg})$, median (min-max) & $15(8-69)$ & $13(8-52)$ \\
\hline \multicolumn{3}{|l|}{ Type of VSD } \\
\hline PMO & 28 & 21 \\
\hline DCSA & 6 & 13 \\
\hline Defect size before a procedure $(\mathrm{mm})$, median (min-max) & $4(2-8)$ & $8(2-16)$ \\
\hline The time of procedure (min), mean (SD) & $108.2(37.8)$ & $157.2(23.0)$ \\
\hline Intervals between procedure monitoring (year), mean (SD) & $1.6(1.3)$ & $1.8(1.3)$ \\
\hline \multicolumn{3}{|l|}{ Follow-up } \\
\hline Mid-term* & 23 & 11 \\
\hline Long-term $^{+}$ & 11 & 23 \\
\hline
\end{tabular}

$\mathrm{SD}=$ standard deviation; VSD=ventricular septal defect; $\mathrm{PMO}=$ perimembranous outlet; $\mathrm{DCSA}=$ doubly committed subarterial

*Mid-term follow-up was done 1-24 months after VSD closure; ${ }^{\dagger}$ long-term follow-up was done 24 months after VSD closure

for the largest proportion of VSD in the transcatheter group, while it was large VSD in the surgical group. Compared with the mean duration time procedure of VSD transcatheter closure, the mean duration time of VSD surgery closure was longer (108.2 versus $157.2 \mathrm{~min}, p<0.001)$. The mean duration time of CPB was 54.7 (range, 38-78) min, and the average crossclamp duration was 30.8 (range, 17-68) min. Surgical approaches used for VSD closure were the right atrial approach and transpulmonary approach, which were performed in 22 and 12 subjects, respectively, and all defect closures were performed using patches. For transcatheter VSD closure, the antegrade approach was employed, and ADO II was used in majority of the cases.

ECG features, valve regurgitation, and residual shunt in subjects before and after VSD closure are shown in Table 2. Prior to VSD closure, all subjects had sinus heart rhythm as well as normal PR interval and QRS duration. Left ventricular hypertrophy was found in 61 subjects, with a larger proportion in the surgical group than in the transcatheter group (33 versus 28).

After VSD closure, arrhythmias were detected in 12 subjects, including 5 subjects in the transcatheter group and 7 subjects in the surgical group $(p=0.732)$. Four subjects experienced arrhythmia during mid-term monitoring. The most common type of arrhythmias after VSD closure was incomplete right bundle branch block (RBBB), which occurred in three and four subjects in the transcatheter and surgical groups, respectively. The largest proportion of patients with arrhythmias was found in subjects with Amplatzer perimembranous VSD occlusion. The number of patients who developed arrhythmias following VSD closure was higher in the surgical group using the right atrial approach technique $(n=5)$ than those using the right atrial and transpulmonary approach $(n=2)$.

Valve regurgitation was observed in 34 subjects prior to VSD closure and was more common in the surgical group $(n=31)$ than in the transcatheter group $(n=3)$. Aortic valve regurgitation occurred in 16 subjects after VSD closure, all of which are trivial/ mild aortic valve regurgitation, and no moderate and severe aortic valve regurgitation were found after both procedures. Tricuspid valve regurgitation occurred in 19 subjects after closure. Increasing severity of valve regurgitation (aortic and tricuspid) before and after both procedures was found in 27 subjects, which was more common in the transcatheter group than in the surgical group (16 versus $11 ; p=0.322$ ). Overall, five subjects (14.7\%) had residual shunt after VSD closure in both groups $(p=1.000)$.

\section{DISCUSSION}

This study showed an increase in the severity of regurgitation after transcatheter $(n=16)$ and surgical 
Table 2. ECG and valve regurgitation features before and after VSD closure and residual shunt features after VSD closure

\begin{tabular}{|c|c|c|c|c|c|c|}
\hline \multirow{4}{*}{ Feature } & \multicolumn{6}{|c|}{ Procedure } \\
\hline & \multicolumn{2}{|c|}{ Before VSD closure } & \multicolumn{4}{|c|}{ After VSD closure } \\
\hline & \multirow[t]{2}{*}{$\begin{array}{l}\text { Transcatheter, } \\
\mathrm{n}(\mathrm{N}=34)\end{array}$} & \multirow[t]{2}{*}{$\begin{array}{l}\text { Surgery, } \\
\mathrm{n}(\mathrm{N}=34)\end{array}$} & \multicolumn{2}{|c|}{$\begin{array}{l}\text { Transcatheter, } \\
\mathrm{n}(\mathrm{N}=34)\end{array}$} & \multicolumn{2}{|c|}{$\begin{array}{l}\text { Surgery, } \\
\mathrm{n}(\mathrm{N}=34)\end{array}$} \\
\hline & & & Mid-term* & Long-term $^{+}$ & Mid-term* & Long-term $^{+}$ \\
\hline \multicolumn{7}{|l|}{ ECG } \\
\hline Sinus rhythm & 34 & 34 & 22 & 7 & 7 & 20 \\
\hline \multicolumn{7}{|l|}{ Arrhythmia } \\
\hline Incomplete RBBB & 0 & 0 & 1 & 2 & 2 & 2 \\
\hline Complete RBBB & 0 & 0 & 0 & 1 & 0 & 1 \\
\hline First-degree AV block & 0 & 0 & 0 & 1 & 1 & 0 \\
\hline Junctional rhythm & 0 & 0 & 0 & 0 & 1 & 0 \\
\hline \multicolumn{7}{|l|}{ Heart rate } \\
\hline Normal & 34 & 34 & 22 & 11 & 8 & 23 \\
\hline Bradycardia & 0 & 0 & 1 & 0 & 3 & 0 \\
\hline \multicolumn{7}{|l|}{ Axis } \\
\hline Left deviation & 0 & 0 & 1 & 0 & 1 & 0 \\
\hline Right deviation & 1 & 2 & 0 & 0 & 1 & 1 \\
\hline Prolonged PR interval & 0 & 0 & 1 & 0 & 1 & 0 \\
\hline Prolonged QRS complex & 0 & 0 & 2 & 2 & 3 & 2 \\
\hline LVH & 28 & 33 & 2 & 2 & 2 & 3 \\
\hline \multicolumn{7}{|l|}{ Valve regurgitation } \\
\hline \multicolumn{7}{|l|}{ Aortic } \\
\hline Trivial/mild & 1 & 16 & 6 & 4 & 1 & 5 \\
\hline Moderate & 0 & 1 & 0 & 0 & 0 & 0 \\
\hline Severe & 0 & 0 & 0 & 0 & 0 & 0 \\
\hline \multicolumn{7}{|l|}{ Tricuspid } \\
\hline Trivial/mild & 2 & 12 & 5 & 0 & 8 & 4 \\
\hline Moderate & 0 & 1 & 0 & 0 & 1 & 0 \\
\hline Severe & 0 & 1 & 0 & 0 & 1 & 0 \\
\hline $\begin{array}{l}\text { Increasing severity reguritasi valve before } \\
\text { and after }\end{array}$ & & & 10 & 6 & 7 & 4 \\
\hline \multicolumn{7}{|l|}{ Residual shunts } \\
\hline No & & & 21 & 8 & 7 & 21 \\
\hline Mild & & & 2 & 3 & 4 & 1 \\
\hline Moderate & & & 0 & 0 & 0 & 0 \\
\hline Severe & & & 0 & 0 & 0 & 0 \\
\hline
\end{tabular}

$\mathrm{ECG}=$ electrocardiography; VSD=ventricular septal defect; RBBB=right bundle branch block; $A V=$ atrioventricular; $L V H=l$ eft ventricular hypertrophy *Mid-term follow-up was done 1-24 months after VSD closure; †long-term follow-up was done 24 months after VSD closure

$(n=11)$ closures of VSD. No severe regurgitation was observed after the closure procedure. Similarly, in a previous study, no subjects developed severe tricuspid regurgitation after surgical VSD closure ${ }^{11}$ which suggested that valve regurgitation complications occurred at a similar rate after transcatheter and surgical closures of VSDs.
A residual shunt was found in $5.9 \%$ of cases after transcatheter VSD closure and in $8.8 \%$ of cases after surgical closure. These results were similar to the findings of a previous study, i.e., residual shunt occurred in $5.4 \%$ of transcatheter cases and in $8.8 \%$ of surgical cases. ${ }^{8}$ In the present study, residual shunts were found on those using APMVO (50\%) and ADO II 
(7.1\%); in the surgical group, they occurred in patients with DCSA VSDs (8.3\%) and in those with moderate VSDs (18.2\%). A previous study revealed that the safety and efficacy of the device used for VSD closure depends on the device suitability and type of defect. ${ }^{12}$

Arrhythmias were found in five and seven subjects who underwent transcatheter and surgical closure of VSDs, respectively. Moreover, in this study, no total AV blocks were found following both VSD closure procedures. These results were similar to the finding of a study in China in which no total AV blocks were found following both VSD closure. ${ }^{10}$ Another study found that total AV block occurred in $3.5 \%$ of subjects who underwent surgical VSD closure, ${ }^{11}$ while other studies in Egypt reported $14 \mathrm{AV}$ blocks in 400 subjects who underwent surgical VSD closure. ${ }^{13}$ Differences in total AV block events in the present study with other studies could be caused by many factors, especially the patient's condition before the procedure and the surgical technique used. ${ }^{8}$ Incomplete RBBB was the most common arrhythmia in both procedures; however, the rates were much lower than those in another study that reported $8.8 \%$ and $2.9 \%$ for transcatheter and surgical closure, respectively. In the present study, the incidence of incomplete RBBB was lower than that in another study, with $19.4 \%$ following transcatheter closure and $82.3 \%$ with surgical closure. ${ }^{11}$ The difference in the incidence rate could be due to the difference in monitoring time. In general, total AV block events did not occur immediately and required a more extended monitoring period. ${ }^{14}$ Arrhythmia was the most common complication of VSD closure. It was caused by compression of the conduction pathway by the device after transcatheter closure or His bundle injury, which is located in the ventricular septum and occurred due to the surgical process. ${ }^{14}$ Monitoring should be done periodically, encompassing mid-term and long-term monitoring, because complications can occur at different periods.

Mean (standard deviation [SD]) age subjects who underwent transcatheter closure were older than those who underwent surgical closure in our study (6.1 [4.4] versus 5.6 [3.4]). Other studies showed a median age of 7.5 versus 4.4 years $^{7}$ and mean age of 9 versus 1.8 years. ${ }^{9}$ Subjects who underwent surgical closure were older than those in other studies, so the complications after surgical closure were fewer than those in other studies. The number of DCSA cases in the surgical group was higher than that in the transcatheter group, i.e., 13 versus 6 . This is because DCSA VSDs are often accompanied by prolapse and aortic valve regurgitation; thus, surgical closure would be the best choice. ${ }^{15}$

In this study, the mean (SD) procedure duration of transcatheter closure was 108.2 (37.8) $\mathrm{min}$, and this value was not much different from those in other studies in Canada wherein the mean (SD) procedure duration for transcatheter and surgical closures was 123 (26.9) min. ${ }^{9}$ In the present study, the mean (SD) fluoroscopy time in the transcatheter group was 27.5 (12.8) min versus 29.89 (12) $\mathrm{min}^{9}$ and 29 (14) $\mathrm{min}^{16}$ in other studies. The mean (SD) procedure duration of surgical closure was 157.2 (23.0) min, which was shorter than those in other studies in China, with a mean (SD) of 180.5 (66.1) $\mathrm{min} .{ }^{14}$ The procedure duration of VSD closure did not affect mid- and longterm complications.

This study had some limitations. First, this was a retrospective cohort study using medical records and some data were unavailable. Second, some children who underwent transcatheter or surgical closure were lost to follow-up. Thus, the results may not represent mid- and long-term complications of VSD closure in Indonesia. A prospective cohort study with larger subjects is needed to assess the duration of arrhythmia, valve regurgitation, and residual shunts. Providing appropriate counseling to the patient and family is necessary, especially for the possibility of arrhythmia after transcatheter and surgical closure of VSD.

In conclusion, the incidence of arrhythmia, increased severity of aortic and tricuspid regurgitation, and the incidence of residual shunt after transcatheter VSD closure was not higher than after surgical VSD closure.

\section{Conflict of Interest}

The authors affirm no conflict of interest in this study.

\section{Acknowledgment}

The authors would like to thank the head and staff of the Integrated Cardiovascular Center Cipto Mangunkusumo Hospital and of Kiara Outpatient Clinic for all the facilities used in this study. We would like to thank the nurses who have helped in this study and all participants who kindly gave their time for our study.

\section{Funding Sources None.}

\section{REFERENCES}

1. Park MK. Pediatric cardiology for practitioners. $6^{\text {th }}$ ed. Philadelphia: Saunders Elsevier; 2014. p. 3-76, 155-84.

2. Gatea SK, Janabi AK. Natural history of isolated ventricular septal defects in the first two years of life. Qatar Med J. 2010;6:147-60. 
3. Chaudhry TA, Younas M, Baig A. Ventricular septal defect and associated complications. J Pak Med Assoc. 2011;61:1001-4.

4. Djer MM, Putra ST, Ulfa A, Roebiono PS, Rahman AR, Noormanto, et al. Penatalaksanaan penyakit jantung bawaan. Jakarta: Departemen Kesehatan RI; 2007. [Indonesian].

5. Arora R, Trehan V, Thakur AK, Mehta V, Sengupta PP, Nigam M. Transcatheter closure of congenital muscular ventricular septal defect. J Interven Cardiol. 2004;17:109-15.

6. Liu J, Wang Z, Gao L, Tan HL, Zheng Q, Zhang ML. A large institutional study on outcomes and complications after transcatheter closure of a perimembranous-type ventricular septal defect in 890 cases. Acta Cardiol Sin. 2013;29:271-6.

7. McDaniel NL. Ventricular and atrial septal defects. Pediat Rev. 2001;22:265-9.

8. Wojtalik MP, Wojtalik M, Mrówczyñski W, Surmacz R. Closure of perimembranous ventricular septal defect using transcatheter technique versus surgical repair. Kardiol Pol. 2005;63:595-602.

9. Oses P, Hugues N, Dahdah N, Vobecky SJ, Miro J, Pellerin $M$, et al. Treatment of isolated ventricular septal defects in children: Amplatzer versus surgical closure. Ann Thorac Surg. 2010;90:1593-8.

10. Yang J, Yang L, Yu S, Liu J, Zuo J, Chen W, et al. Transcatheter versus surgical closure of perimembranous ventricular septal defects in children: a randomized controlled trial. J Am Coll Cardiol. 2014;63:1159-68.

11. Narin N, Baykan A, Argun M, Özyurt A, Pamukçu Ö, Sezer $A$, et al. Single-center results of the use of transcatheter closure forventricular septal defects. Turk Gogus Kalp Dama. 2015;23:448-53.

12. Bol-Raap G, Weerheim J, Kappetein AP, Witsenburg M, Bogers AJJC. Follow-up after surgical closure of congenital ventricular septal defect. EJCTS. 2003;24:511-5.

13. Azab S, El-Shahawy H, Samy A, Mahdy W. Permanent complete heart block following surgical closure of isolated ventricular septal defect. Egypt J Chest Dis Tuberculosis. 2013;62:529-33

14. Yang J, Yang L, Wan Y, Zuo J, Zhang J, Chen W, et al. Transcatheter device closure of perimembranous ventricular septal defects: mid-term outcomes. Eur Heart J. 2010;31:2238-45.

15. Waqar T, Rizvi MFA, Baig AR. Doubly committed subarterial ventricular septal defect repair: an experience of 51 cases. Pak J Med Sci. 2017;33(5):1112-6.

16. Butera $G$, Chessa M, Carminati M. Percutaneous closure of ventricular septal defects. State of the art. J Cardiovasc Med. 2007;8:39-45. 